Research Paper

\title{
Partial Müllerian Duct Retention in Smad4 Conditional Mutant Male Mice
}

\author{
Fabrice G. Petit ${ }^{1}{ }^{2}$, Chuxia Deng 3 , Soazik P. Jamin ${ }^{1,2}{ }^{\circledR}$ \\ 1. Institut National de la Santé et de la Recherche Médicale, Institut de Recherche en Santé, Environnement et Travail, UMR1085, Université de Rennes 1, \\ Rennes, France; \\ 2. Institut National de la Santé et de la Recherche Médicale, U782, Clamart, France. \\ 3. Faculty of Health Sciences, University of Macau, Macau SAR, China. \\ $\square$ Corresponding author: soazik.jamin@inserm.fr.
}

(1) Ivyspring International Publisher. Reproduction is permitted for personal, noncommercial use, provided that the article is in whole, unmodified, and properly cited. See http://ivyspring.com/terms for terms and conditions.

Received: 2015.04.01; Accepted: 2016.02.17; Published: 2016.04.21

\begin{abstract}
Müllerian duct regression is a complex process which involves the AMH signalling pathway. We have previously demonstrated that besides $\mathrm{AMH}$ and its specific type II receptor (AMHRII), BMPR-IA and Smad5 are two essential factors implicated in this mechanism.

Mothers against decapentaplegic homolog 4 (Smad4) is a transcription factor and the common Smad (co-Smad) involved in transforming growth factor beta (TGF- $\beta$ ) signalling pathway superfamily. Since Smad4 null mutants die early during gastrulation, we have inactivated Smad4 in the Müllerian duct mesenchyme. Specific inactivation of Smad4 in the urogenital ridge leads to the partial persistence of the Müllerian duct in adult male mice. Careful examination of the urogenital tract reveals that the Müllerian duct retention is randomly distributed either on one side or both sides. Histological analysis shows a uterus-like structure, which is confirmed by the expression of estrogen receptor $\alpha$. As previously described in a $\beta$-catenin conditional mutant mouse model, $\beta$-catenin contributes to Müllerian duct regression. In our mutant male embryos, it appears that $\beta$-catenin expression is locally reduced along the urogenital ridge as compared to control mice. Moreover, the expression pattern is similar to those observed in control female mice. This study shows that reduced Smad4 expression disrupts the $W n t / \beta$-catenin signalling leading to the partial persistence of Müllerian duct.
\end{abstract}

Key words: Smad4, Müllerian duct, conditional knockout, $\beta$-catenin.

\section{Introduction}

At the indifferent stage, the foetus possesses a bipotential gonad and two pairs of ducts: the Müllerian duct and the Wolffian duct. During development, the Wolffian duct forms first and elongates in an anteroposterior direction. After its formation, the Müllerian duct grows from rostral to caudal and joins the urogenital sinus. In the female, the Müllerian duct gives rise to the oviduct, uterus and upper part of the vagina. Under the influence of testosterone the Wolffian duct differentiates into the vas deferens, epididymis and seminal vesicle in males [1].

Müllerian duct regression is an active developmental process involving anti-Müllerian hormone $(\mathrm{AMH})$ and its specific receptor AMHR-II [2, 3]. $\mathrm{AMH}$ is a glycoprotein that belongs to the transforming growth factor beta (TGF- $\beta$ ) family [4]. It is secreted by foetal Sertoli cells during male sexual differentiation. Like the other members of the TGF- $\beta$ family, AMH transduces its effects through two transmembrane serine/threonine kinase receptors type I and II, and two types of cytoplasmic effectors, specific Smads (R-Smads), and a Smad protein common to all ligands, Smad4 [5]. The signalling pathway downstream of AMH in the Müllerian duct is now well documented: it involves mainly the bone morphogenetic protein receptor type IA (BMPR-IA, also named ALK3) and Smad1/Smad5 proteins [6, 7]. 
However, although Smad4 is described as the common Smad, several studies suggest that BMP and TGF- $\beta$ signalling can be independent of Smad4 $[8,9]$.

Smad4 is involved in numerous developmental processes including early development, cell growth, differentiation and pathologies like cancer. Because of its major role during gastrulation [10, 11], Smad4 deficient embryos cannot form preventing post-natal analysis of Smad4 functions. In addition, haploid loss of Smad4 in mice triggers gastric cancer [12]. To circumvent this, mice bearing a Smad4 floxed allele were produced to allow the generation of different conditional mutant mice [13-15].

Among the numerous important functions exerted by BMP family members during development, Müllerian duct regression is a very specific process, which occurs exclusively in males between E13.5 and E15.5 in mice [2]. The aim of this study is to determine the potential involvement of Smad4 during this process. We have designed a specific deletion of Smad4 in the Müllerian duct using the Cre-lox system by crossing the Amhr2-Cre

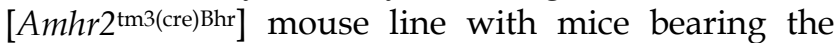
Smad4 floxed allele [Smad4tm2.1Cxd] $[6,15]$. We then analysed the phenotype of the conditional mutant males both macroscopically and at the cellular level. We show that males display a consistent phenotype indicating that Smad4 might play a role in the completion of Müllerian duct regression.

\section{Materials and Methods}

\section{Mice}

Amhr2-Cre (Amhr2tm3(cre)Bhr) and Smad4 floxed mice (Smad4tm2.1Cxd) were maintained on a C57BL/6J; $129 / \mathrm{SvEv}$ mixed genetic background as previously described [6, 15]. Amhr2+/cre mice were crossed with Smad4f/f to generate Amhr2+/cre; Smad4 ${ }^{+/ f}$ mice. These mice were then mated with Smad4f/f female mice to generate the $A m h r 2^{+/ c r e} ; S m a d 4^{\mathrm{f} / \mathrm{f}}$ conditional knockout mice (Smad4 cKO, noted Smad4 $\left.4^{\Delta / \Delta}\right)$. The Smad4 $4^{\mathrm{f} / \mathrm{f}}$ littermates were used as control mice. Genotyping was performed on DNA from tail biopsies or amniotic sac using standard PCR protocols. Mice used for the experiments were genotyped twice, at weaning and at sacrifice respectively, in order to confirm the genotype.

\section{RNA isolation and PCR amplification}

For regular PCR, total RNAs from E14.5 mesonephri were isolated using the RNeasy Plus Mini kit (Qiagen) according to the manufacturer's instructions. Reverse transcription was performed in a total of $20 \mu \mathrm{l}$ with the High capacity RNA-to-cDNA ${ }^{\mathrm{TM}}$ Kit for RT-PCR (Life Technologies) using $125 \mathrm{ng}$ total
RNA. The samples were incubated $1 \mathrm{~h}$ at $37^{\circ} \mathrm{C}$ and inactivation was performed for $5 \mathrm{~min}$ at $95^{\circ} \mathrm{C}$. PCR was performed using HotStarTaq Plus DNA Polymerase (Qiagen) according to the manufacturer's instructions. The amplification conditions were $95^{\circ} \mathrm{C}$ for $5 \mathrm{~min}$, followed by 35 cycles at $94^{\circ} \mathrm{C}$ for $45 \mathrm{~s}, 58^{\circ} \mathrm{C}$ for $45 \mathrm{~s}$, and $72^{\circ} \mathrm{C}$ for $45 \mathrm{~s}$, with a final extension at $72^{\circ} \mathrm{C}$ for $10 \mathrm{~min}$. The amplified PCR fragments were analysed on $2 \%$ agarose gels and visualized with ImageQuant 350 (GE Healthcare).

Primer sequences. Amhr2-Cre: PTMWbpA-s: CGC ATT GTC TGA GTA GGT GT. mAmhr2 E5-a: GAA ACG CAG CTC GGC CAG C. Smad4: Q-mSmad4-1368-s: CAG-CCT-CCC-ATT-TCC-AAT-C. Q-m-Smad4-1694-a: GCC-AGC-TTC-TCT-GTC-CAGGT.

For real time PCR, $200 \mathrm{ng}$ of total RNAs from E14.5 mesonephri were isolated using Arcturus PicoPure RNA isolation kit (Thermo Fisher Scientific) and reverse transcription was performed using iScript cDNA synthesis kit (Bio-Rad) following the manufacturer's instructions. The synthesis was achieved at $42^{\circ} \mathrm{C}$ for $30 \mathrm{~min}$ and heat inactivated at $85^{\circ} \mathrm{C}$ for $5 \mathrm{~min}$. Real time PCR was set up with iTaq Universal SYBR Green supermix (Biorad) and run in a Bio-Rad CFX384 apparatus. Samples were analyzed in duplicates with one-tenth dilution of the cDNAs. The PCR program was $95^{\circ} \mathrm{C}$ for $3 \mathrm{~min}$ for initial denaturation, then 40 cycles as follows $95^{\circ} \mathrm{C}$ for $10 \mathrm{sec}$ and $60^{\circ} \mathrm{C}$ for $30 \mathrm{sec}$. The melting curve was generated by heating from $65^{\circ} \mathrm{C}$ to $95^{\circ} \mathrm{C}$. Standard curves were generated with increasing dilutions of a control cDNA template. Relative gene expression was normalized to an endogenous control gene ( $R p l 13 a)$.

Primer sequences. Smad4: Q-m-Smad4-1482-s: ACT-GTG-GAT-GGC-TAT-GTG-GAT. Q-m-Smad41594-a: CCT-TTG-CCT-ATG-TGC-AAC-CT. Rpl13a: Q-m-Rpl13a-458-s: CAT-GAG-GTC-GGG-TGG-AAGTA. Q-m-Rpl13a-573-a: GCC-TGT-TTC-CGT-AACCTC-AA.

\section{Histology, Immunohistochemistry (IHC) and Immunofluorescence (IF)}

Reproductive tracts were collected from male mice at 3 weeks, 3 months and 12 months in PBS and visualized under a Zeiss stereomicroscope Stereo Discovery V8 connected to an Axiocam ICc3 camera. Uteri from mature female mice in oestrus were collected to serve as controls. Embryos at E14.5 were dissected out in PBS and the amniotic sac was used for genotyping. All samples were fixed overnight at $4^{\circ} \mathrm{C}$ in $4 \%$ paraformaldehyde before the procedure of dehydration and embedding in paraffin. $5 \mu \mathrm{m}$ sections were rehydrated and then the antigen was unmasked (Antigen Unmasking Solution, Vector 
Laboratories).

For IHC, the endogenous peroxydase activity was quenched and a blocking solution $1.5 \%$ goat serum or MOM Mouse Ig Blocking reagent (Vector Laboratories), 1x PBS and Avidin D, Vector Laboratories) was applied for $60 \mathrm{~min}$. Sections were incubated overnight at $4^{\circ} \mathrm{C}$ with the primary antibody diluted into a solution containing $1.5 \%$ goat serum in PBS or a MOM protein concentrate (Vector Laboratories) and Biotin (Vector Laboratories). After several washes with PBS, the secondary goat anti-rabbit or a MOM biotinylated anti-mouse antibody (Vector Laboratories) was added onto the sections for $60 \mathrm{~min}$. The signal was amplified using the $\mathrm{ABC}$ kit (Vector Laboratories), the DAB substrate (Sigma) was applied and the sections were counterstained with Harris hematoxylin (Leica Microsystems).

For IF, specimen were blocked in blocking buffer (1x PBS, 2\% BSA, 0.3\% Triton $^{\mathrm{TM}} \mathrm{X}-100$ ) for $60 \mathrm{~min}$. A primary antibody diluted into the antibody dilution buffer (1x PBS, 1\% BSA, 0.3\% Triton ${ }^{\mathrm{TM}}$ X-100) was applied overnight at $4^{\circ} \mathrm{C}$. After 3 washes in PBS, sections are incubated with the secondary antibody (Life Technologies, AlexaFluor 594, 1:500) in the antibody dilution buffer. After 3 washes in PBS, VectaShield Hard Set Antifade Mounting Medium with DAPI (Vector Laboratories) is added before coverslipping.

The primary antibody used were as follow: a rabbit monoclonal anti-Smad4 C-terminal antibody (Abcam, ab40759, 1:100), a rabbit polyclonal anti-estrogen receptor $\alpha$ antibody (Santa Cruz, sc7207, 1:200), a rabbit monoclonal anti E-cadherin antibody (Cell Signaling, 3195, 1:400), a rabbit monoclonal anti-LEF1 antibody (Cell Signaling, 2230, 1:400), a rabbit monoclonal anti $\beta$-catenin antibody (Abcam, ab32572, 1:800) and a mouse monoclonal anti $\alpha$-SMA antibody (Sigma, T7451, 1:800).

\section{Ethical Statement}

Housing and care, method of euthanasia and experimental protocols were conducted in accordance with the recommendations of the French Accreditation of Laboratory Animal Care and in compliance with the NIH Guide for Care and Use of Laboratory Animals. The animal facility is licensed by the French Ministry of Agriculture (agreement C35-238-19). All animal experiments were supervised by Dr. Soazik Jamin and Dr. Fabrice Petit (agreement delivered by the French Ministry of Agriculture for animal experiment \# 92-299 and \# A92-313, respectively). Animals were sacrificed with $\mathrm{CO}_{2}$. All efforts were made to minimize animal suffering.
A

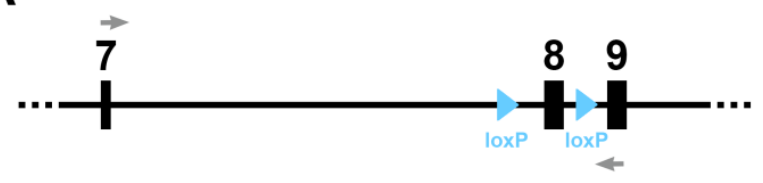

B
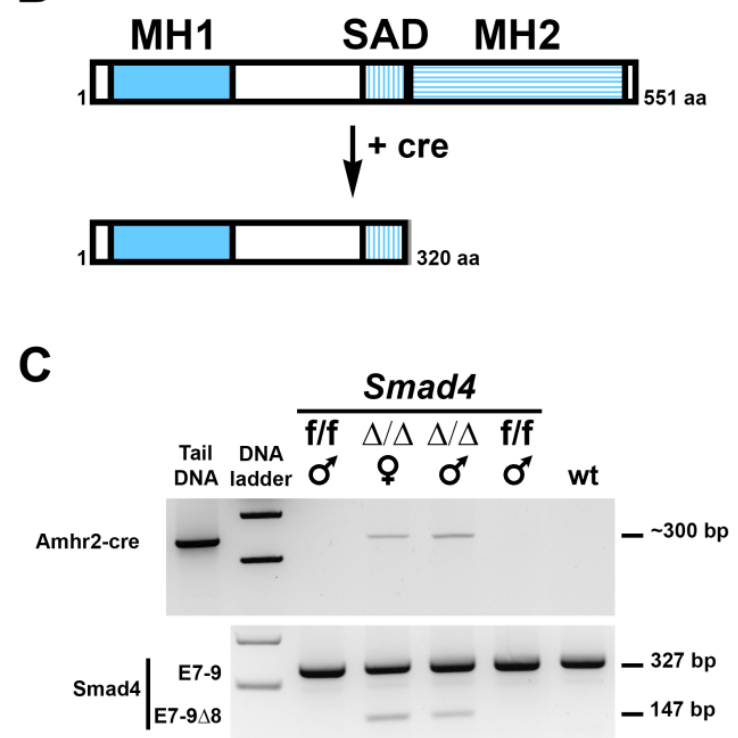

Figure 1. Conditional deletion of exon 8 of the Smad4 gene in the gonadal ridges of 14.5 dpc Smad4 cKO embryos. (A) schematic diagram of the Smad4 conditional allele (exon 7 to 9) showing lox P sites flanking exon 8. Grey arrows represent the primers used to distinguish the full length Smad 4 mRNA from the $\Delta 8$ Smad4 mRNA. (B) Like other Smad proteins, Smad4 possesses two conserved regions, $\mathrm{MH} 1$ and $\mathrm{MH} 2$ (MAD homology 1 and 2 ) separated by a linker region SAD (Smad4 Activation Domain). MHI domain exhibits sequence-specific DNA-binding, while $\mathrm{MH} 2$ is responsible for heteromerization and transactivation functions. Deletion of Smad4 exon 8 using a Cre-expressing mouse leads to the production of a truncated Smad4 protein missing the MH2 domain. (C) RT-PCR on Cre (top panel) and Smad4 (bottom panel) products shows that Cre-expressing mice (Smad4 $\Delta / \Delta$, noted $\Delta / \Delta$ ) possess the full-length (327 bp) and the truncated (147 bp) RNA. Smad4f/f $(\mathrm{f} / \mathrm{f})$ and wt mice were used as controls. Tail DNA from a Cre-expressing mouse was used as a positive control for the Cre.

\section{Results}

To address the role of Smad4 during Müllerian duct regression, we have generated conditional mutant male mice lacking Smad4 in the mesenchyme surrounding the epithelium of the duct. The Smad4 conditional allele was generated by flanking exon 8 with 2 loxP sites (Fig. 1A) [15]. Specific deletion of floxed Smad4 alleles in the mesenchyme of the urogenital ridge is accomplished by using a Cre line expressing the recombinase under the control of Amhr2 (Amhr2-Cre) [6]. We crossed Amhr2+/cre; $\mathrm{Smad4}^{+/ \mathrm{f}}$ males with Smad4f/f females to generate Amhr2 $2^{+/ \text {cre}}$ S Smad4 $4^{\mathrm{f} / \mathrm{f}}$ male mice $\left(\operatorname{Smad} 4^{\Delta / \Delta}\right)$. Deletion of exon 8 leads to the expression of a truncated Smad4 protein, which lacks the MH2 domain (Fig. 1B) and therefore cannot bind other Smad proteins, transcription factors, coactivators and corepressors [16]. We first checked Smad4 deletion in the Müllerian duct using RT-PCR on mesonephri. We found that in 
addition to the wild-type allele (327 bp) a mutated allele (147 bp) was generated (Fig. 1C, bottom panel). This short PCR product indicates that the recombination occurred in the desired tissue. As a control, we show that the corresponding individuals express Cre recombinase driven by the Amhr2 promoter (Fig. 1C, top panel).

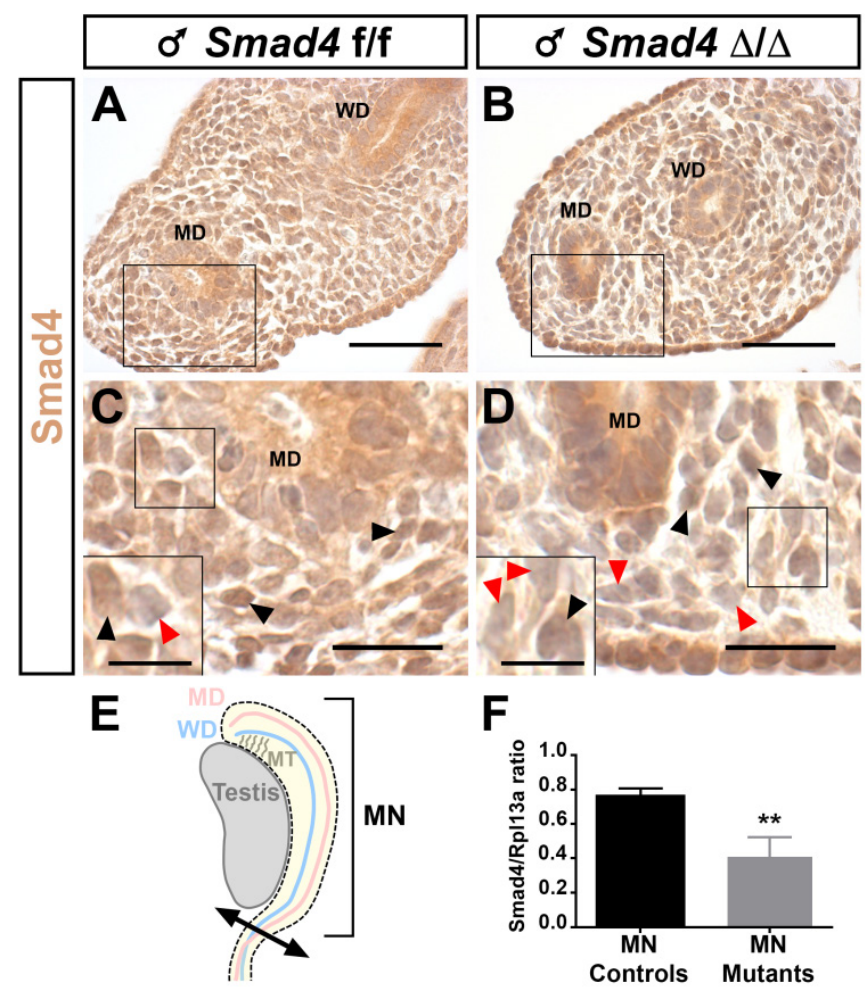

Figure 2. Smad4 expression in the E14.5 male mouse urogenital ridge. Paraffin-embedded sections are incubated in presence of anti-Smad4 Ct antibody. (A, C) Nuclear Smad4 expression is detected in the mesenchymal compartment surrounding the Müllerian duct and Wolffian duct of control Smad4/f/ embryos. (B, D) Partial Smad4 expression is observed in the mesenchymal cells of the urogenital ridge of mutant Smad4 $\Delta / \Delta$ embryos. (C, D) High magnifications of the respective marked areas in A and B. Inserts in the bottom left corner are higher magnifications of the marked area. Black arrowheads point to Smad4 expressing cells and red arrowheads point to non-expressing cells. (E) Schematic representation of the embryonic testis and adjacent mesonephros (MN), which was used for RNA extraction and subsequent real-time PCR. (F) The level of Smad4 expression was measured using real-time PCR. Rpll 3a was used to normalize the results. Data were analyzed using paired $t$-test followed by Mann-Whitney test. ** $\mathrm{p}<0.01$. Smad4 expression is significantly decreased in conditional mutant mesonephri compared to controls. Scale bars, $20 \mu \mathrm{m}$ (A-D) and $10 \mu \mathrm{m}$ (inserts in $C$ and $D$ ). MD, Müllerian duct; MN, mesonephros; MT, mesonephric tubules; WD, Wolffian duct.

Since the $S m a d 4^{\Delta / \Delta}$ mice express a C-terminally truncated Smad4 protein, we used a Smad4 antibody directed against the $C$ terminal part of Smad4 to discriminate the cells expressing full-length Smad4 from those that express the truncated protein by immunohistochemistry. As expected, at embryonic day 14.5 (E14.5) Smad4 is widely expressed in the urogenital ridge including the Wolffian duct and Müllerian duct (Fig. 2A and C). In Smad4 $4^{\Delta / \Delta}$ embryos, the full-length Smad4 protein level is only partially reduced since some mesenchymal cells still express Smad4 (Fig. 2B and D). The quantification of Smad4 expression was achieved on embryonic mesonephri isolated from three individuals (Fig. 2E). After RNA extraction and reverse transcription, real-time PCR was performed on control and mutant mesonephri. Rpl13a expression was used for the internal control. As shown in Fig. 2F, Smad4 expression was significantly decreased by two fold in mutant mesonephri indicating that the recombination occurred in this organ.

As expected, the generation of $\operatorname{Smad} 4^{\Delta / \Delta}$ mice is not perturbed by the specific inactivation of Smad4 in the urogenital ridge and the gonads. $S m a d 4^{\Delta / \Delta}$ mice are viable but the reproductive functions differ in females and males. Mutant females are infertile (Petit et al., in preparation) and mutant males are fertile. Indeed, the overall reproductive performance of the mutant males was not affected. They regularly have pups and the litter size did not show any significant differences between control $(7.2 \pm 1.8, \mathrm{n}=10)$ and mutant $(7.3 \pm 1.9, \mathrm{n}=24)$. The macroscopic and detailed observation of immature (3-week-old) or mature (3and 12-month-old) $S m a d 4^{\Delta / \Delta}$ male mice shows that they retain a partial Müllerian duct as compared to control Smad4f/f (Fig. 3). The presence of these Müllerian duct remnants is observed in all individuals regardless of age but their number and location may vary from one to another. Indeed, we observed one Müllerian duct remnant on one side (Fig. 3E, F, O, P, $\mathrm{Q}$ and R) or two sides (Fig. 3I, J, J', K and L), and two on one side (Fig. 3C, D). They are located anywhere along the vas deferens and they persist throughout the mouse life without apparent alteration. Note that control Smad4f/f males never exhibit any partial Müllerian duct remnant (Fig. 3A, B, G, H, M and N). Moreover, Amhr2+/cre; Smad4 $4^{+/ \mathrm{f}}$ males do not present any Müllerian duct retention (data not shown).

To further characterize the identity of the Müllerian duct remnant, we performed a histological analysis by staining the transverse sections with hematoxylin/eosin on mature mice (Fig. 4). As a control, we used a previously described pseudohermaphrodite male [6] (Amhr2cre/cre), in which the disruption of $\mathrm{AMH}$ signalling pathway leads to the persistence of the whole Müllerian duct alongside the Wolffian duct (Fig. 4A-C). Normal development of either the vas deferens or the uterus was shown using a Smad4f/f male (Fig. 4D) and a $S m a d 4^{+/ \Delta}$ female (Fig. $4 \mathrm{E})$. We find that the vas deferens of mutant males (Fig. 4F) has the same histological features than the vas deferens from pseudohermaphrodite (Fig. 4A) and control (Fig. 4D) male mice. In addition, they all contain spermatozoa indicating that the testis is fully functional. We also analysed the Müllerian duct remnants, which are in close contact with the vas deferens (Fig. 4G). 


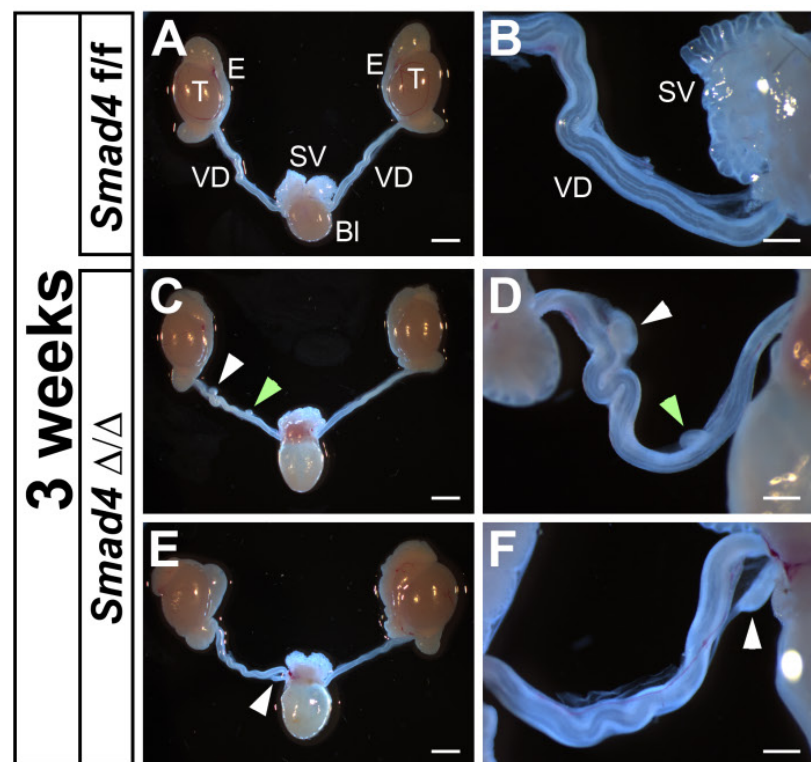

Figure 3. Partial Müllerian duct retention in Smad4 $\Delta / \Delta$ mutant mice. The observation of control Smad4/f male mice at different ages shows a normal development of the reproductive tract with a complete regression of Müllerian duct (A, G, M). However, in Smad4 $\Delta / \Delta$ mutant reproductive tracts, a persistence of small Müllerian duct parts is observed uni- or bilaterally (C, E, I, K, O, Q, white and green arrowheads). Note that for Smad4 $\Delta / \Delta$, two different mice per age are shown. (B, D, F, $\mathrm{H}, \mathrm{J}-\mathrm{J}$, $\mathrm{L}, \mathrm{N}, \mathrm{P}, \mathrm{R})$ Higher magnifications of $\mathrm{A}, \mathrm{C}, \mathrm{E}, \mathrm{G}, \mathrm{I}, \mathrm{K}, \mathrm{M}, \mathrm{O}$ and $\mathrm{Q}$, respectively. Scale bars, 2 mm (A, C, E, G, I, K, M, O, Q), 1 mm (H, J, J', L, N, P, R) and $500 \mu \mathrm{m}$ (B, $\mathrm{D}, \mathrm{F})$. BI, bladder; E, epididymis; SV, seminal vesicles; T, testis; VD, vas deferens.

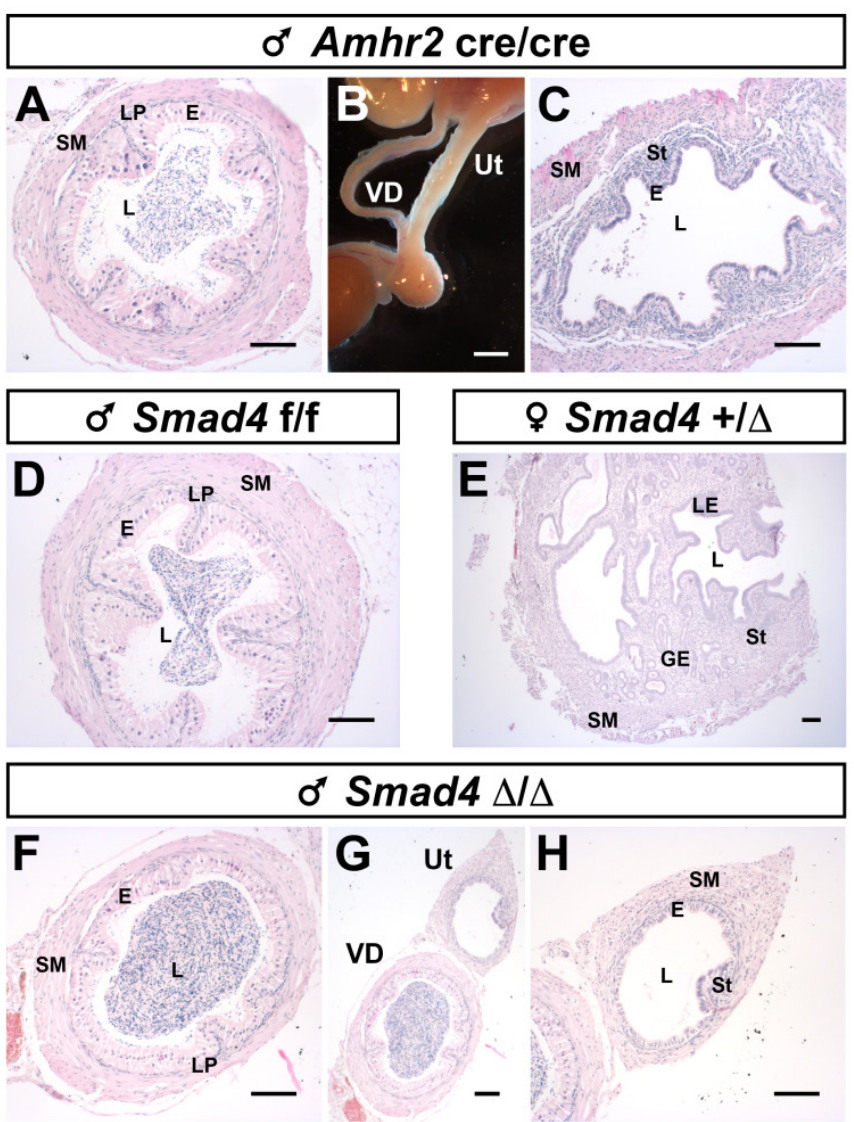

Figure 4. Müllerian duct remnants in $\operatorname{Smad4} \Delta / \Delta$ mutant mice develop as uteri. Disruption of the AMH pathway in mature Amhr2cre/cre male mice causes retention of the whole Müllerian duct alongside the Wolffian duct. The Müllerian duct and Wolffian duct will develop as uterus and vas deferens, respectively (B). Paraffin embedded sections of vas deferens and uterus stained with hematoxylin/eosin ( $A, C$, $D-H)$. Vas deferens and uterus from Amhr2cre/cre male mouse $(A, C)$. Mature Smad4/f/f male (D) and Smad4 $+/ \Delta$ female (E) mice present a fully developed vas deferens and uterus, respectively. In mature Smad $4 \Delta / \Delta$ mutant mice $(\mathrm{F}-\mathrm{H})$, the vas deferens appears normal. Although, the Müllerian duct can develop as a uterus, it is smaller than a normal uterus and often underdeveloped (compare $H$ with $E$ ). Scale bars, $2 \mathrm{~mm}$ (B) and $100 \mu \mathrm{m}$ (A, C, D-H). E, epithelium; GE, glandular epithelium; L, lumen; LE, luminal epithelium; LP; lamina propria; SM, smooth muscle; St, stroma; Ut, uterus; VD, vas deferens.

Histologically, all remnants display layers comparable to a normal uterus, including smooth muscle, epithelium and stroma (Fig. $4 \mathrm{H}$ versus $4 \mathrm{E}$ ). Nevertheless, one can notice that the stromal compartment is greatly underdeveloped. We have also checked the identity and responsiveness of the uterus using immunostaining for the estrogen receptor alpha (ER $\alpha$ or NR3A1, Fig. 5B and F). As expected, ER $\alpha$ is highly expressed in the cellular 
nucleus of all compartments (epithelium, stroma and myometrium) both in control female and mutant male [17]. On the other hand, the epithelial compartment of the vas deferens does not express ER $\alpha$ (Fig. 5A and E). The different muscle layers both in the vas deferens and in the uterus are marked with $\alpha$ smooth muscle actin antibody ( $\alpha$ SMA) (Fig. $5 C, D, G$ and $H$ ). This characteristic expression pattern of ER $\alpha$ combined to those of $\alpha \mathrm{SMA}$ confirms that the Müllerian duct remnant has a uterus-like structure. As observed in Fig. $4 \mathrm{H}, 5 \mathrm{~F}$ and $5 \mathrm{H}$ the absence of a glandular epithelium and a developed stromal compartment delineates an immature uterus, which was not exposed to estrogens [18].

As previously shown in a $\beta$-catenin mutant mouse model [19], it appears that $\beta$-catenin is required for Müllerian duct regression. In addition, during Müllerian duct regression $\beta$-catenin and Lef1 accumulates in the nucleus of mesenchymal cells [2]. Therefore, to delineate the possible origin of Müllerian duct remnants in our Smad4 ${ }^{\Delta / \Delta}$ mouse model, we performed an immunofluorescence assay on E14.5 urogenital ridge sections to analyse the expression of $\beta$-catenin and Lef1 (Fig. 6). To delineate the mesenchyme from the epithelium, we used an antibody directed against E-cadherin. As previously described [20], E-cadherin is uniformly expressed in the coelomic epithelium including the Wolffian duct and the cells bordering the urogenital ridge (Fig. 6C, $\mathrm{F}, \mathrm{I}, \mathrm{L}$ and $\mathrm{O}$ ). In the urogenital ridge of control female mice, strong membranous expression of $\beta$-catenin in the Müllerian duct, Wolffian duct and coelomic epithelium was observed (Fig. 6A). In control male mice, $\beta$-catenin protein is not only detected in the epithelium compartment but also in the mesenchyme surrounding the Müllerian duct (Fig. 6D). Since Müllerian duct remnants in mutant male mice can be observed anywhere alongside the Wolffian duct, we have analysed different sections along the urogenital ridge for $\beta$-catenin expression (Fig. $6 \mathrm{G}, \mathrm{J}$ and $\mathrm{M}$ ). It appears that the majority of sections show a similar expression pattern to the one observed in control male mice (Fig. 6J and $\mathrm{M}$ versus $6 \mathrm{D}$ ). Nevertheless, it is interesting to note that a dramatic reduced expression of $\beta$-catenin is observed in some sections (Fig. 6G). Moreover, the expression pattern observed in this section is similar to the one analysed in female (Fig. $6 \mathrm{G}$ versus 6A). The expression analysis of the Wnt/ $\beta$-catenin target gene Lef1 [21] reveals an absence of immunodetection in sections (Fig. $6 \mathrm{~B}$ and $\mathrm{H})$, where $\beta$-catenin is downregulated in the Müllerian duct mesenchyme (Fig. 6A and G). However, Lef1 is nicely induced in the $\beta$-catenin-expressing mesenchyme surrounding the
Müllerian duct (Fig. 6D/E, J/K and M/N). One can note that a reduced expression of $\beta$-catenin (Fig. $6 \mathrm{~J}$ ) is correlated with a reduced Lef1 signal (Fig. 6K). This observation suggests that the Wnt/ $\beta$-catenin signalling pathway is locally abolished along the Müllerian duct mesenchyme of mutant male mice.

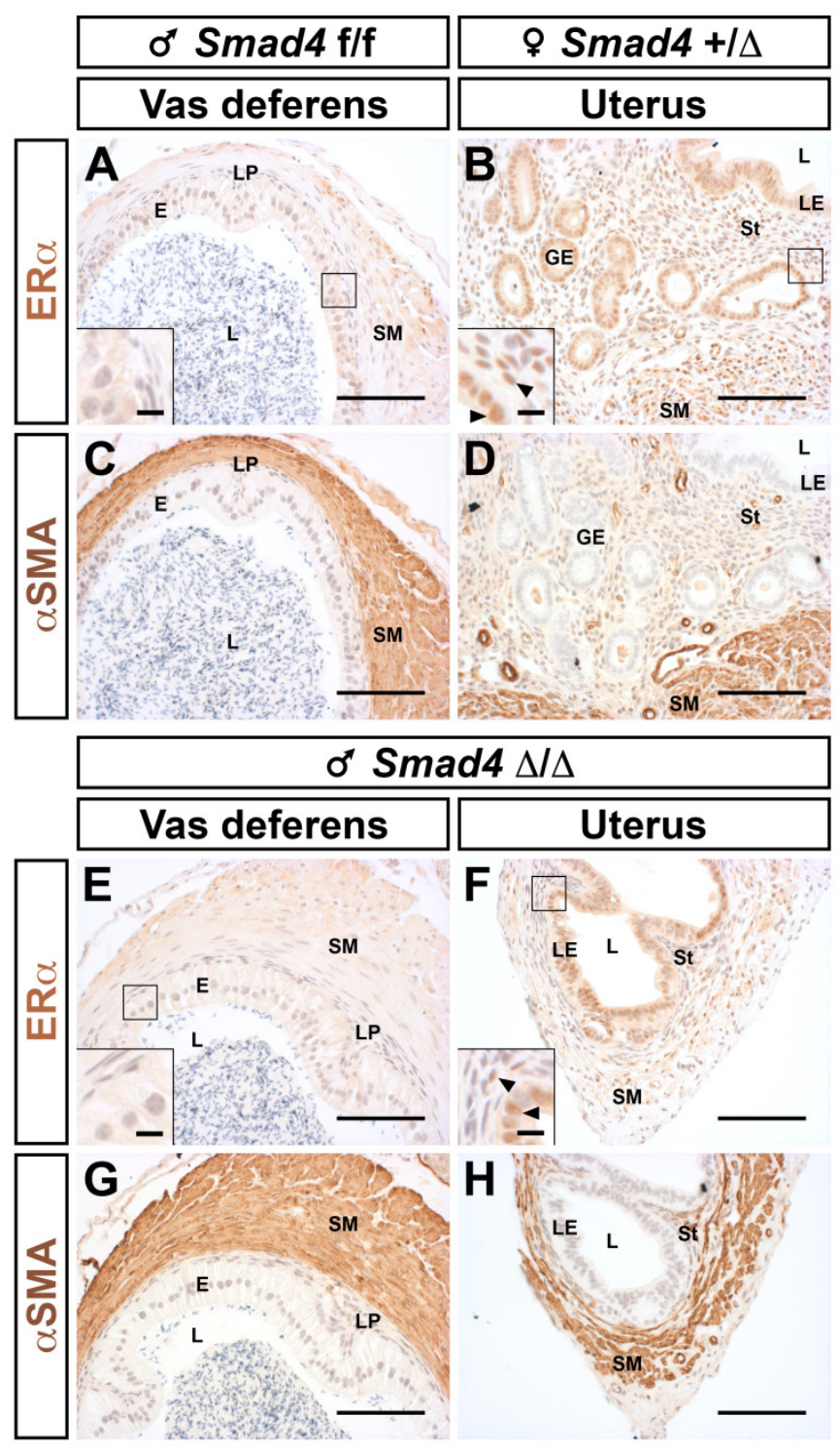

Figure 5. Müllerian duct remnants from Smad4 conditional mutant male display all histological characteristics of a uterus. Immunostaining for ER $\alpha$ showed that nuclei of the uterine luminal epithelium are marked ( $B$ and $F$ ) but not nuclei of vas deferens ( $A$ and $E$ ). The smooth muscle layers are delineated using a $\alpha$ smooth muscle actin ( $\alpha$ SMA) antibody $(C, D, G$ and $H$ ). Inserts in the bottom left corner of $A, B, E$ and $F$ are higher magnifications of the respective marked area. Arrowheads point to ER $\alpha$ positive cells Scale bars, $100 \mu \mathrm{m}(\mathrm{A}-\mathrm{H})$ and $10 \mu \mathrm{m}$ (inserts in $A, B, E$ and $F$ ). $E$, epithelium; GE, glandular epithelium; L, lumen; LE, luminal epithelium; LP; lamina propria; SM, smooth muscle; St, stroma. 

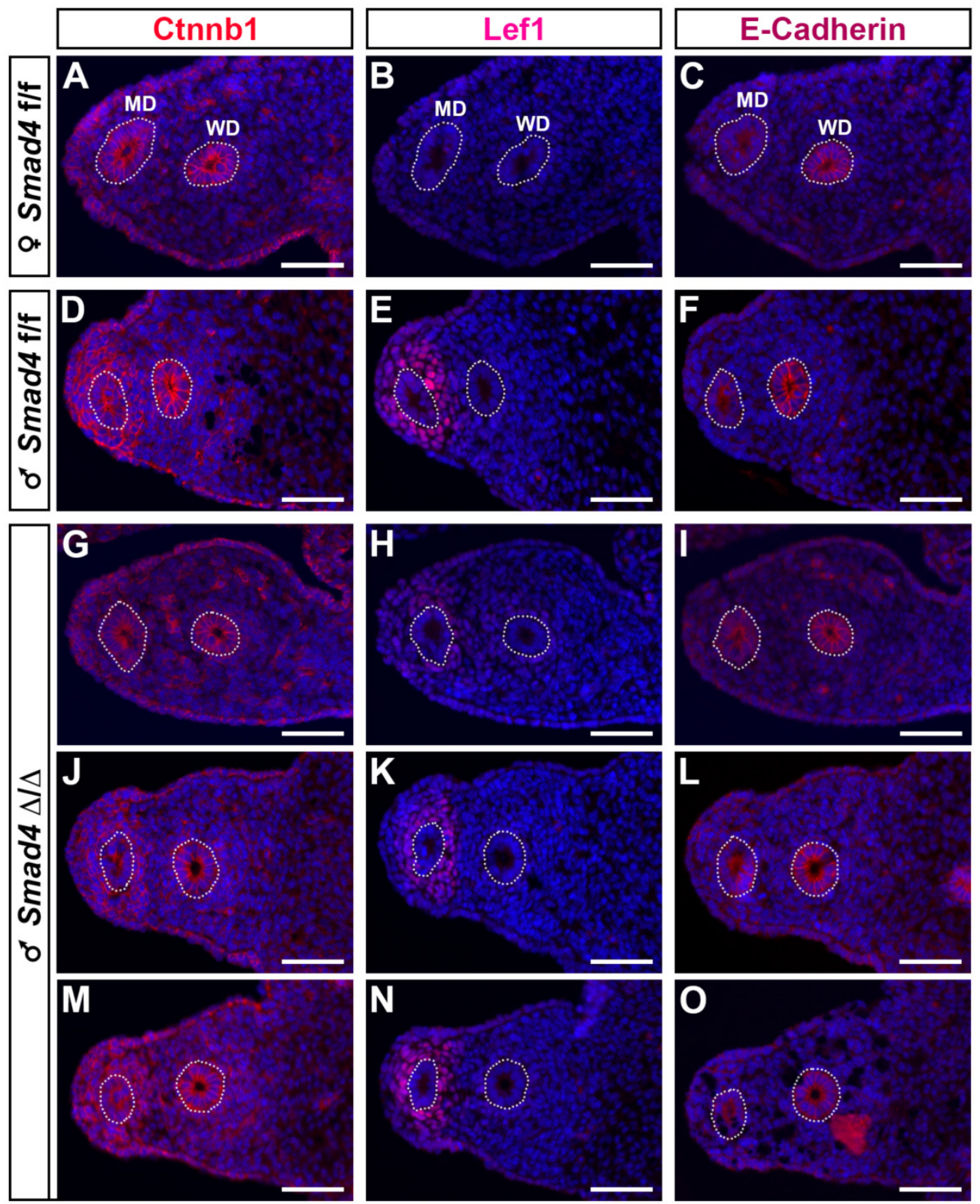

Figure 6. Local reduced expression of $\beta$-catenin in the urogenital ridge of the Smad4 ${ }^{\Delta / \Delta}$ mutant male. E14.5 male and female urogenital ridges were analyzed by immunofluorescence (red) for the expression of $\beta$-catenin (Ctnnbl, A, D, G, J, M), Lefl, a Wnt/ $\beta$-catenin target molecule (B, E, H, K, N) and E-cadherin, an epithelium marker (C, F, I, L, O). DAPI staining (blue) was used to delineate the nuclei. In el4.5 Smad4fff female urogenital ridge, $\beta$-catenin expression is localized to the cell membrane of the Müllerian duct and Wolffian duct epithelium (A) and Lefl is not expressed (B). In Smad4fff male, $\beta$-catenin is expressed in the Müllerian duct and Wolffian duct epithelium, as well as in the mesenchyme surrounding the Müllerian duct (D), where Lefl is also strongly expressed. In Smad4 ${ }^{\Delta \Delta}$ male, different sections along the mesonephros show that $\beta$-catenin expression is conserved in the Müllerian duct and Wolffian duct epithelium (G, J, M), but not in the Müllerian duct mesenchymal compartment $(G<J<M)$. In $M$, the level of expression is similar to the one observed in the control male (D). The expression of $\beta$-catenin is correlated with those of Lefl (H, K, N). Scale bars, $50 \mu \mathrm{m}$. MD, Müllerian duct; WD, Wolffian duct.

\section{Discussion}

In this study, we have generated conditional mutant mice lacking Smad4 in the mesenchyme surrounding the Müllerian duct using a strategy comparable to what we previously performed $[6,7]$. Since Smad4 is the common Smad involved in BMP and activin/TGF- $\beta$ signalling pathways [5], we hypothesized that it might play a central role in the pathway downstream of AMH. Therefore, in our Smad4 conditional knockout mouse model we expected to have a similar phenotype to what was observed in conditional mutants for $S m a d 1 / 5$ or Actr1a/Bmpr1a [6, 7, 22-24]. Conditional double mutants for Smad1/5 and Actr1a/Bpmr1a display a complete Müllerian duct retention leading to the formation of a uterus as it was described for Amh and Amhr2 homozygous mutant male mice $[25,26]$. 
Surprisingly, we observe that Smad4 deletion in the mesenchyme of the Müllerian duct leads to the partial but consistent retention of Müllerian duct remnants. The mosaic Smad4 expression could explain the apparent weak involvement of Smad4 in the AMH pathway and the partial retention phenotype observed. Despite these observations, one can note that the persistence is fully penetrant since it is observed in all animals tested. In the Amh-Amhr2-Bmpr1a-Smad1/5/8 gene activation cascade, Smad4 is considered as an important factor helping the phosphorylated Smads1/5/8 translocate to the nucleus, where the heterodimeric complex Smad1/5/8-Smad4 transcriptionally activates its target genes [27]. This pathway plays a primordial role for Müllerian duct regression since inactivation of one of these factors is sufficient to maintain the Müllerian duct, which gives rise to a uterus [1]. However, in our study the incomplete Smad4 gene inactivation shows a moderate effect on Müllerian duct retention. Since Smad4 deletion is likely mosaic along the Müllerian duct, Smad4 expression is variable throughout this axis. We hypothesize that, in order to observe a retention, Smad4 expression must be under a critical threshold, which is reached in one or two regions of the Müllerian duct. A similar observation has been previously reported for Amh [28]. These authors show that SF1-binding site mutation in Amh promoter leads to a dramatic reduction of Amh transcript levels (about 80\%). Nevertheless, these homozygous mutant males have no Müllerian duct retention [28].

These observations do not exclude that other factors compensate for the loss of Smad4 or act in a Smad4-independent manner as it is reported for Trim33 or DROSHA [29, 30]. During palate development, TGF- $\beta 3$ plays a critical role for epithelial fusion. A recent study has shown that TGF- $\beta 3$ signalling involves a Smad-dependent pathway both Smad4 dependent and Smad4 independent [30]. More specifically, phosphorylated Smad2 can bind either Smad4 or Trim 33, the two pathways being essential for the correct epithelial fusion during palatogenesis [30]. Another study has shown that miRNA processing is independent of Smad4 while it depends on the presence of R-Smads [29].

As previously shown, the deletion of exon 8 leads to the formation of a truncated Smad4 protein lacking 198 amino acids in the C-terminal domain, which encompasses the MH2 domain (Fig. 1B) [11, 15]. Several studies have demonstrated that this truncated protein cannot transmit activin/TGF- $\beta$ or BMP signals showing that this Smad4 mutation is identical to a null mutation [31-36]. However, since the truncated Smad4 protein retains its DNA binding domain and therefore its ability to interact with the Smad-binding element [37], one cannot exclude that this mutant protein is biologically active. Indeed, it has been shown that the $\mathrm{N}$-terminal domain is capable of reporter gene transactivation in yeast and mammalian cells $[37,38]$ and it can interact with $\mathrm{CBP} / \mathrm{p} 300$ [39]. A dominant negative form is also worth considering since a MH1-containing truncated Smad4 protein reduces the tumor growth in mice [40]. Moreover, mutations leading to a $\mathrm{MH} 2$-truncated Smad4 have been reported. This protein has been described as a dominant negative form and is found in patients diagnosed with cancer due to an alteration of the TGF- $\beta$ signalling pathway [41-43]. In the Smad4 conditional mutant mice mimicking the knockout mice $[11,15]$, it is possible that the first function of Smad4 is disrupted in the absence of a fully functional protein and the truncated Smad4 protein does not interfere with any transcriptional activity. However, in our conditional mouse model, the presence of a truncated protein might be sufficient to perturb the action of other transcription factors. Therefore, diminishing the transcriptional activity of factors involved in the Müllerian duct development probably reduces the effect of Smad4 gene inactivation in the urogenital ridge.

A similar phenotype of partial Müllerian duct retention was observed in males expressing constitutively active $\beta$-catenin (CA $\beta$-catenin) [44]. In newborn males expressing and accumulating $\mathrm{CA}$ $\beta$-catenin in the mesenchyme surrounding the Müllerian duct, focal Müllerian duct remnants were present and persisted through adulthood. This focal Müllerian duct retention was explained by a delayed expression of CA $\beta$-catenin due to an Amhr2-Cre expression occurring after the Müllerian duct regression has already started [44]. Nevertheless, Behringer's group has shown that the use of Amhr2-Cre mice to conditionally inactivate $\beta$-catenin in the mesenchyme surrounding the Müllerian duct results in total Müllerian duct retention [19]. Consequently, it appears that $\beta$-catenin participates in the process of Müllerian duct regression in male mice. Therefore, it is conceivable that what is thought to be focal Müllerian duct retention in CA $\beta$-catenin expressing mice [44] is more likely an incomplete Müllerian duct regression. Like in our study, the location of Müllerian duct remnants varies between individuals. These variations might be due to the mosaic expression of the Cre recombinase driven by Amhr2 [19]. From these data it seems that Smad4 can modulate the $\beta$-catenin expression in the mesenchyme surrounding the Müllerian duct in male mice and interfere with Müllerian duct regression. Therefore, it 
is worth considering that any mutation in Smad4 leading to an inactive or truncated form may affect the Müllerian duct regression and lead to PMDS. Currently several mutations of Smad4 resulting in truncated proteins have been shown to affect the functions of other Smad proteins [31, 32, 45].

\section{Abbreviations}

$\mathrm{AMH}$, anti-Müllerian hormone; AMHRII, AMH type II receptor; $\mathrm{BMP}$, bone morphogenetic protein; DAB, diaminobenzidine; PBS, Phosphate buffered saline; RT-PCR, reverse transcriptase polymerase chain reaction; Smad, Sma- and Mad-related protein; Wnt, wingless-type MMTV integration site family.

\section{Acknowledgments}

We are grateful to Richard R. Behringer (MD Anderson Cancer Center, Houston, TX, USA) for the initiation of this study in his laboratory and for supplying us with the Amhr2-Cre mice. We are grateful to Michael Primig for allowing the termination of this work. We thank Nassim Arouche for his technical assistance with PCR. These studies were supported by l'Institut National de la Santé et de la Recherche Médicale and the grant from l'Agence Nationale de la Recherche awarded to S.P.J. [grant number ANR-08- JCJC-0059].

\section{Competing Interests}

The authors have declared that no competing interest exists.

\section{References}

1. Josso N, Cate RL, Picard JY, Vigier B, di Clemente N, Wilson C, et al. Anti-Mullerian hormone: the Jost factor. Recent Prog Horm Res. 1993; 48: 1-59.

2. Allard S, Adin P, Gouédard L, di Clemente N, Josso N, Orgebin-Crist MC, et al. Molecular mechanisms of hormone-mediated Müllerian duct regression: involvement of beta-. Development. 2000; 127: 3349-60.

3. Mullen RD, Behringer RR. Molecular genetics of Mullerian duct formation, regression and differentiation. Sexual development : genetics, molecular biology, evolution, endocrinology, embryology, and pathology of sex determination and differentiation. 2014; 8: 281-96.

4. Josso N, di Clemente N. Transduction pathway of anti-Müllerian hormone, a sex-specific member of the TGF-beta family. Trends Endocrinol Metab. 2003; 14: 91-7.

5. Massagué J, Seoane J, Wotton D. Smad transcription factors. Genes \& development. 2005; 19: 2783-810.

6. Jamin SP, Arango NA, Mishina Y, Hanks MC, Behringer RR. Requirement of Bmpr1a for Mullerian duct regression during male sexual development. Nature genetics. 2002; 32: 408-10.

7. Orvis GD, Jamin SP, Kwan KM, Mishina Y, Kaartinen VM, Huang S, et al. Functional redundancy of TGF- $\beta$ family Type I receptors and receptor-Smads in mediating $\mathrm{AMH}-$-induced Müllerian duct regression in the mouse. Biology of reproduction. 2008; 78: 994-1001.

8. Morikawa Y, Zehir A, Maska E, Deng C, Schneider MD, Mishina Y, et al. BMP signaling regulates sympathetic nervous system development through Smad4-dependent and -independent pathways. Development. 2009; 136: 3575-84.

9. Xu X, Han J, Ito $\mathrm{Y}$, Bringas $\mathrm{P}, \mathrm{Jr}$., Deng C, Chai $\mathrm{Y}$. Ectodermal Smad4 and p38 MAPK are functionally redundant in mediating TGF-beta/BMP signaling during tooth and palate development. Developmental cell. 2008; 15: 322-9.

10. Sirard C, de la Pompa JL, Elia A, Itie A, Mirtsos C, Cheung A, et al. The tumor suppressor gene Smad4/Dpc4 is required for gastrulation and later for anterior development of the mouse embryo. Genes \& development. 1998; 12: 107-19.

11. Yang $X, \mathrm{Li} C, \mathrm{Xu} X$, Deng C. The tumor suppressor SMAD4/DPC4 is essential for epiblast proliferation and mesoderm induction in mice. Proceedings of the
National Academy of Sciences of the United States of America. 1998; 95: 3667-72.

12. Xu X, Brodie SG, Yang X, Im YH, Parks WT, Chen L, et al. Haploid loss of the tumor suppressor Smad4/Dpc4 initiates gastric polyposis and cancer in mice. Oncogene. 2000; 19: 1868-74.

13. Bardeesy N, Cheng KH, Berger JH, Chu GC, Pahler J, Olson P, et al. Smad4 is dispensable for normal pancreas development yet critical in progression and tumor biology of pancreas cancer. Genes \& development. 2006; 20: 3130-46.

14. Chu GC, Dunn NR, Anderson DC, Oxburgh L, Robertson EJ. Differential requirements for Smad4 in TGFbeta-dependent patterning of the early mouse embryo. Development. 2004; 131: 3501-12.

15. Yang X, Li C, Herrera PL, Deng CX. Generation of Smad4/Dpc4 conditional knockout mice. Genesis. 2002; 32: 80-1.

16. Liu F, Pouponnot C, Massague J. Dual role of the Smad4/DPC4 tumor suppressor in TGFbeta-inducible transcriptional complexes. Genes \& development. 1997; 11: 3157-67.

17. Winuthayanon W, Hewitt SC, Orvis GD, Behringer RR, Korach KS. Uterine epithelial estrogen receptor alpha is dispensable for proliferation but essential for complete biological and biochemical responses. Proceedings of the National Academy of Sciences of the United States of America. 2010; 107: 19272-7.

18. Quarmby VE, Korach KS. The influence of 17 beta-estradiol on patterns of cell division in the uterus. Endocrinology. 1984; 114: 694-702.

19. Kobayashi A, Stewart CA, Wang Y, Fujioka K, Thomas NC, Jamin SP, et al. beta-Catenin is essential for Mullerian duct regression during male sexual differentiation. Development. 2011; 138: 1967-75.

20. Orvis GD, Behringer RR. Cellular mechanisms of Mullerian duct formation in the mouse. Developmental biology. 2007; 306: 493-504.

21. Filali M, Cheng N, Abbott D, Leontiev V, Engelhardt JF. Wnt-3A/beta-catenin signaling induces transcription from the LEF-1 promoter. The Journal of biological chemistry. 2002; 277: 33398-410.

22. Clarke TR, Hoshiya Y, Yi SE, Liu X, Lyons KM, Donahoe PK. Mullerian inhibiting substance signaling uses a bone morphogenetic protein (BMP)-like pathway mediated by ALK2 and induces SMAD6 expression. Molecular endocrinology. 2001; 15: 946-59.

23. Gouédard L, Chen YG, Thevenet L, Racine C, Borie S, Lamarre I, et al. Engagement of bone morphogenetic protein type IB receptor and Smad1 signaling by anti-Müllerian hormone and its type II receptor. The Journal of biological chemistry. 2000; 275: 27973-8.

24. Visser JA, Olaso R, Verhoef-Post M, Kramer P, Themmen AP, Ingraham HA. The serine/threonine transmembrane receptor ALK2 mediates Müllerian inhibiting substance signaling. Molecular endocrinology. 2001; 15: 936-45.

25. Behringer RR, Finegold MJ, Cate RL. Mullerian-inhibiting substance function during mammalian sexual development. Cell. 1994; 79: 415-25.

26. Mishina Y, Rey R, Finegold MJ, Matzuk MM, Josso N, Cate RL, et al. Genetic analysis of the Mullerian-inhibiting substance signal transduction pathway in mammalian sexual differentiation. Genes \& development. 1996; 10: 2577-87.

27. Zhan Y, Fujino A, MacLaughlin DT, Manganaro TF, Szotek PP, Arango NA, et al. Mullerian inhibiting substance regulates its receptor/SMAD signaling and causes mesenchymal transition of the coelomic epithelial cells early in Mullerian duct regression. Development. 2006; 133: 2359-69.

28. Arango NA, Lovell-Badge R, Behringer RR. Targeted mutagenesis of the endogenous mouse Mis gene promoter: in vivo definition of genetic pathways of vertebrate sexual development. Cell. 1999; 99: 409-19.

29. Davis BN, Hilyard AC, Lagna $G$, Hata A. SMAD proteins control DROSHA-mediated microRNA maturation. Nature. 2008; 454: 56-61.

30. Lane J, Yumoto K, Azhar M, Ninomiya-Tsuji J, Inagaki M, Hu Y, et al. Tak1, Smad4 and Trim33 redundantly mediate TGF-beta3 signaling during palate development. Developmental biology. 2015; 398: 231-41.

31. Lagna G, Hata A, Hemmati-Brivanlou A, Massague J. Partnership between DPC4 and SMAD proteins in TGF-beta signalling pathways. Nature. 1996; 383: 832-6.

32. Zhang Y, Musci T, Derynck R. The tumor suppressor Smad4/DPC 4 as a central mediator of Smad function. Current biology : CB. 1997; 7: 270-6.

33. Hahn SA, Schutte M, Hoque AT, Moskaluk CA, da Costa LT, Rozenblum E, et al. DPC4, a candidate tumor suppressor gene at human chromosome 18q21.1. Science. 1996; 271: 350-3.

34. McClatchey AI, Saotome I, Ramesh V, Gusella JF, Jacks T. The Nf2 tumor suppressor gene product is essential for extraembryonic development immediately prior to gastrulation. Genes \& development. 1997; 11: 1253-65.

35. Nagatake M, Takagi Y, Osada H, Uchida K, Mitsudomi T, Saji S, et al. Somatic in vivo alterations of the DPC4 gene at $18 \mathrm{q} 21$ in human lung cancers. Cancer research. 1996; 56: 2718-20.

36. Schutte M, Hruban RH, Hedrick L, Cho KR, Nadasdy GM, Weinstein CL, et al. DPC4 gene in various tumor types. Cancer research. 1996; 56: 2527-30.

37. Stroschein SL, Wang W, Luo K. Cooperative binding of Smad proteins to two adjacent DNA elements in the plasminogen activator inhibitor-1 promoter mediates transforming growth factor beta-induced smad-dependent transcriptional activation. The Journal of biological chemistry. 1999; 274: 9431-41.

38. Wu RY, Zhang Y, Feng XH, Derynck R. Heteromeric and homomeric interactions correlate with signaling activity and functional cooperativity of Smad3 and Smad4/DPC4. Molecular and cellular biology. 1997; 17: 2521-8. 
39. Janknecht R, Wells NJ, Hunter T. TGF-beta-stimulated cooperation of smad proteins with the coactivators CBP/p300. Genes \& development. 1998; 12: 2114-9.

40. Paez-Pereda M, Giacomini D, Refojo D, Nagashima AC, Hopfner U, Grubler $\mathrm{Y}$, et al. Involvement of bone morphogenetic protein 4 (BMP-4) in pituitary prolactinoma pathogenesis through a Smad/estrogen receptor crosstalk. Proceedings of the National Academy of Sciences of the United States of America. 2003; 100: 1034-9.

41. Howe JR, Roth S, Ringold JC, Summers RW, Jarvinen HJ, Sistonen P, et al. Mutations in the SMAD4/DPC4 gene in juvenile polyposis. Science. 1998; 280: 1086-8.

42. Ju HR, Jung U, Sonn CH, Yoon SR, Jeon JH, Yang Y, et al. Aberrant signaling of TGF-beta1 by the mutant Smad4 in gastric cancer cells. Cancer letters. 2003; 196: 197-206.

43. Powell SM, Harper JC, Hamilton SR, Robinson CR, Cummings OW. Inactivation of Smad4 in gastric carcinomas. Cancer research. 1997; 57: 4221-4.

44. Tanwar PS, Zhang L, Tanaka Y, Taketo MM, Donahoe PK, Teixeira JM. Focal Mullerian duct retention in male mice with constitutively activated beta-catenin expression in the Mullerian duct mesenchyme. Proceedings of the National Academy of Sciences of the United States of America. 2010; 107: 16142-7.

45. Chen Y, Yee D, Magnuson T. A novel mouse Smad4 mutation reduces protein stability and wild-type protein levels. Mammalian genome : official journal of the International Mammalian Genome Society. 2006; 17: 211-9. 